\title{
Endowing Nanozymes High Biocatalytic Selectivity by Substrates Channeling and Screening
}

Qing Zhou, Hong Yang, Xinghua Chen, Yuan Xu, Dan Han, Sisi Zhou, Songqin Liu, Yanfei Shen, Yuanjian Zhang

Submitted date: 11/05/2020 - Posted date: 12/05/2020

Licence: CC BY-NC-ND 4.0

Citation information: Zhou, Qing; Yang, Hong; Chen, Xinghua; Xu, Yuan; Han, Dan; Zhou, Sisi; et al. (2020): Endowing Nanozymes High Biocatalytic Selectivity by Substrates Channeling and Screening. ChemRxiv. Preprint. https://doi.org/10.26434/chemrxiv.12279947.v1

As an alternative to surmount the weakness of natural enzymes, nanozymes have recently attracted extensive attention from early disease diagnosis to tumor therapy. However, due to the lack of enzyme-like molecular recognition units, the poor substrate selectivity of nanozyme-catalyzed reaction significantly restricts their widespread applications. By biomimicking the ingenuity of metabolism process in living, herein we report a multiple-nanozymes system capable of improving the substrate selectivity via cascade reactions in a confined space. As a showcase, the nitrogen-doped carbon nanocages (NCNC) and Prussian blue nanoparticles (PB NPs) were successfully coupled in a microfluidic device to highly selective oxidation and detection of ascorbic acid (AA, an important electron donor and catalyst for alleviation of oxidative stress) against other interferences. It was revealed that the products of the prior nanozymatic reaction were effectively screened as the reactants of the next one, thus stepwise improving the overall selectivity of the all-nanozyme system. This work may open a new door to improve the selectivity of all-nanozyme-system for prospect applications.

File list (2)

Manuscript.pdf (672.28 KiB)

view on ChemRxiv - download file 


\title{
Endowing Nanozymes High Biocatalytic Selectivity by Substrates \\ Channeling and Screening
}

Qing Zhou, Hong Yang, Xinghua Chen, Yuan Xu, Dan Han, Sisi Zhou, Songqin Liu, Yanfei Shen, Yuanjian Zhang*

Jiangsu Engineering Laboratory of Smart Carbon-Rich Materials and Device, Jiangsu Province Hi-Tech Key Laboratory for Bio-Medical Research, School of Chemistry and Chemical Engineering, Medical School, Southeast University, Nanjing 211189, China. E-mail: Yuanjian.Zhang@seu.edu.cn

\begin{abstract}
As an alternative to surmount the weakness of natural enzymes, nanozymes have recently attracted extensive attention from early disease diagnosis to tumor therapy. However, due to the lack of enzyme-like molecular recognition units, the poor substrate selectivity of nanozyme-catalyzed reaction significantly restricts their widespread applications. By biomimicking the ingenuity of metabolism process in living, herein we report a multiple-nanozymes system capable of improving the substrate selectivity via cascade reactions in a confined space. As a showcase, the nitrogen-doped carbon nanocages (NCNC) and Prussian blue nanoparticles (PB NPs) were successfully coupled in a microfluidic device to highly selective oxidation and detection of ascorbic acid (AA, an important electron donor and catalyst for alleviation of oxidative stress) against other interferences. It was revealed that the products of the prior nanozymatic reaction were effectively screened as the reactants of the next one, thus stepwise improving the overall selectivity of the all-nanozyme system. This work may open a new door to improve the selectivity of all-nanozyme-system for prospect applications.
\end{abstract}




\section{Introduction}

As macromolecular biological catalysts, natural enzymes have attracted much attention due to their high catalytic efficiency and strong substrate selectivity under mild reaction conditions. ${ }^{[1-5]}$ However, some intrinsic shortcomings, e.g. arising from the difficulty in operation of production and purification, low stability during preservation and strict reaction condition, greatly limit their application in industrial reaction systems that are often complicated and even harsh. ${ }^{[6-8]}$ Since the breakthrough discovery of $\mathrm{Fe}_{3} \mathrm{O}_{4}$ nanoparticles with peroxidase-like activity, ${ }^{[9]}$ a large number of nanozymes, such as noble metal, ${ }^{[10-12]}$ metal oxides, ${ }^{[13-16]} 2 \mathrm{D}$ matters ${ }^{[17]}$ and nanocarbon ${ }^{[18-22]}$ have been continually developed for mimicking the enzyme-like functions. These multifarious nanozymes are low-cost, high-stable and mass-produced, which in a sense well surmount the weakness of natural enzymes, thus have already gain prospective applications in biosensing, disease therapy and environmental treatment. ${ }^{[23-27]}$ Nonetheless, as lack of specialized molecular conformation in natural enzymes, nanozyme-driven reactions demonstrated a poor substrate selectivity, one of the biggest obstacles that restricted their widespread applications.

Along this line, a few interesting attempts were carried out to address this critical issue. For instance, natural enzymes and molecular imprinting technique were reported to cascade with and house nanozymes, respectively, both of which significantly improve the selectivity of the nanozymatic reactions. ${ }^{[28-32]}$ However, the selectivity either still strongly relied on the natural enzymes rather than nanozymes themselves or was largely impeded by the limited functional monomers and complicated operations. Therefore, developing nanozyme system with high selectivity remains challenging and appeals for new strategies.

As known, after millions of years of evolution, the signaling and energy conversion/storage reactions such as metabolism of alcohols in livings are highly precise and efficient, in which the participation of a variety of cascade enzymes plays a vital role (Figure 1a). ${ }^{[33-34]}$ Moreover, these biocatalytic reactions often occur in confined space, such as cellular compartment. It not only endows the products of the 
prior step as the reactants of the next step but also prevents the potential loss/conversion of these intermediate species via futile diffusion into the ambient medium. ${ }^{[35-39]}$ This greatly inspires us to cascade a certain of nanozymes with a specific sequence in a confined space, by which, the products of the prior step are screened as the reactants of the next step, thus stepwise improving the overall selectivity of the reaction system (Figure 1b).

Herein, we report an all-nanozyme-system that highly select substrate enabled by cascade reactions between nitrogen-doped carbon nanocages (NCNC) and Prussian blue nanoparticles (PB NPs) in a microfluidic chip. Two keys to implementing this approach was revealed, i.e. the rational selection of types of nanozymes with appropriate catalytic properties and the engineering of a specific sequence. As a proof of concept application, the NCNC and PB NPs were coated into a spatially confined reaction channel in a continuous flow microfluidic device for highly selective and sensitive monitor of ascorbic acid against other interferent antioxidants.

\section{Results and discussion}

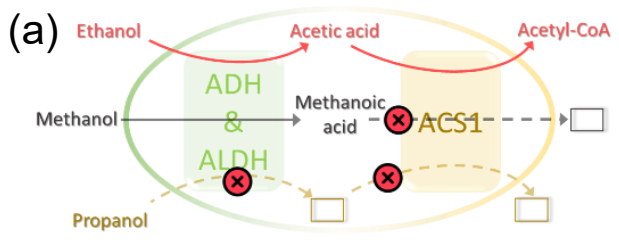

(b)

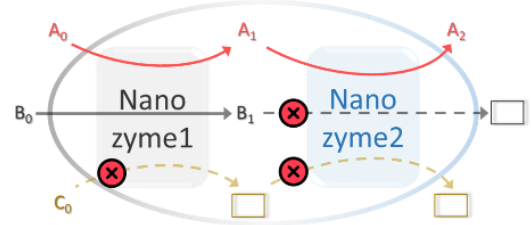

Figure 1. (a) An example of cascade reaction occurring in the alcohols metabolism. ADH: Alcohol dehydrogenase; ALDH: Aldehyde dehydrogenase; ACS1: Acetyl-CoA synthase 1. (b) Biomimicking high-selective dual-nanozyme system.

Figure $1 \mathrm{~b}$ demonstrated the principle of improving the reaction selectivity by cascading a couple of nanozymes in a spatially confined space. In general, a variety of substrates could be catalytically oxidized by Nanozyme-1, despite some not. In this sense, merely relying on a single Nanozyme-1, the selectivity of the reaction system 
was poor. For this, Nanozyme-2 was arranged to catalyze the second reaction using the prior product by Nanozyme- 1 as the substrate. When molecule $\mathrm{A}_{0}$ can run into the two cascade reactions via $A_{1}$ as the intermediate species, the final product $A_{2}$ can be ready observed. In fact, not all molecules can pass through these two catalytic cascade reactions, due to the substrates screening. For instance, molecule $\mathrm{B}_{0}$ may also be catalytically oxidized by Nanozyme- 1 under the same condition, but the product $\mathrm{B}_{1}$ is not capable of triggering the posterior reaction. The third possibility is that molecule $\mathrm{C}_{0}$ cannot be catalyzed by Nanozyme-1 at all, i.e. neither of cascade reactions are initiable. By following this principle, the substrate selectivity by this dual- or more sophisticated multiple-nanozyme system would be improved, which was similar to that in the metabolism of alcohols.

Nonetheless, there are three grand challenges to construct such delicate cascade nanozymes system. One is the choice of a series of nanozymes with different biocatalytic abilities. The second is the arrangement of the sequence of biocatalytic reactions by nanozymes. Along this line, the product by the prior nanozyme is possible to be the substrate for the posterior one, resulting in nanozymatic cascade reactions. Lastly but not less important, the possible interference among these biocatalytic reactions should be strictly avoided.

In this work, the oxidase-like NCNC and the peroxidase-like PB NPs were employed as the showcase nanozymes, as they can easily connected by using $\mathrm{H}_{2} \mathrm{O}_{2}$ as the intermediate species, like the couple of glucose oxidase (GOX) and (HRP) in many highly selective sensing studies. The NCNC was prepared using the $\mathrm{MgO}$ template method with pyridine as the precursor at $800{ }^{\circ} \mathrm{C} .{ }^{[40]}$ The TEM and SEM images showed the typical morphology and hierarchical porous structure of the NCNC (Figure 2a and Figure S1). Notably, the 3D flower-like particles of ca. $5 \mu \mathrm{m}$ assembled into micrometer-sized nanosheets, meanwhile which were further made into the cuboidal hollow nanocages with the shell thickness of ca. $2.5 \mathrm{~nm}$ and the size of 15 20 nm. Such unique morphology and multiscale porous structure were favorable for accomplishing high specific surface area and accelerating the mass transport, so as to boost the efficiency of the nanozymatic reactions. ${ }^{[41-42]}$ 

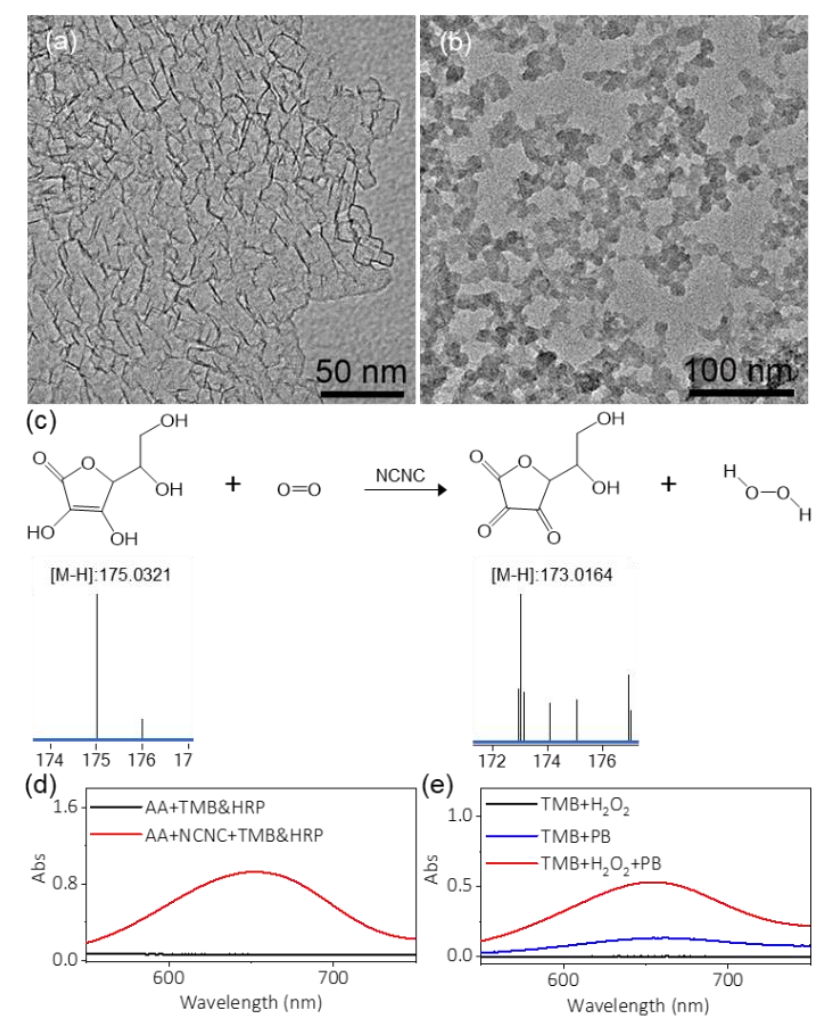

Figure 2. TEM images of (a) NCNC and (b) PB NPs. (c) Reaction pathway of AA oxidation catalyzed by NCNC and ESI-MS spectra of AA and $A_{A} A_{o x}$. (d) UV-vis spectra of $\mathrm{TMB}_{\text {ox }}$ catalyzed by HRP in the presence of $\mathrm{AA}$ and $\mathrm{TMB}_{\text {ox }}$ catalyzed by HRP with the generated $\mathrm{H}_{2} \mathrm{O}_{2}$ during the catalyzation of AA by NCNC. (e) UV-Vis absorption spectra of $\mathrm{TMB}_{\text {ox }}$ oxidized by $\mathrm{H}_{2} \mathrm{O}_{2}, \mathrm{TMB}_{\text {ox }}$ catalyzed oxidation by PB NPs, and $\mathrm{TMB}_{\mathrm{ox}}$ catalyzed oxidation by PB NPs with $\mathrm{H}_{2} \mathrm{O}_{2}$.

To evaluate the nanozyme catalytic activity of NCNC, the catalytic oxidation of AA with $\mathrm{O}_{2}$ was explored in the first set of experiments. The electrospray ionization mass spectral analysis demonstrated that before the oxidation the fragment of AA, i.e. [M-H]', appeared at 175.0225 (Figure 2c); in contrast, it exclusively down-shifted to 173.0164 after the oxidation, indicating the dehydrogenation of two -OH moieties on AA into $\mathrm{AA}_{0 x}\left(\mathrm{C}_{6} \mathrm{H}_{6} \mathrm{O}_{6}\right.$, Figure 2c). The reduction product of $\mathrm{O}_{2}$ during the AA oxidation, was further examined. For this, the TMB-HRP kit that is highly responsive to $\mathrm{H}_{2} \mathrm{O}_{2}$ was employed. As shown in the UV-vis absorption spectra (Figure 2d), an evident absorption peak at $652 \mathrm{~nm}$ ascribed to the $\mathrm{TMB}^{+}$cation radical of $\mathrm{TMB}_{\mathrm{ox}}$ was exclusively observed with the participation of NCNC; ${ }^{[43]}$ meanwhile, such absorbance was proportional to the concentration of AA (Figure S2a\&2b). These facts evident verified that NCNC catalyzed the oxidation of AA along with production of $\mathrm{H}_{2} \mathrm{O}_{2}$. 
Besides, NCNC showed a stable biocatalytic performance under a series of harsh $\mathrm{pH}$ and high-temperature attack (Figure S3). In this context, NCNC had excellent oxidaselike properties, which can catalyze the oxidization of AA with the participation of molecular oxygen, generating $\mathrm{H}_{2} \mathrm{O}_{2}$ and $\mathrm{AA}_{\mathrm{ox}}$ (E.q. 1, Figure S2d). Some previous reports demonstrated that $\mathrm{O}_{2}$ could be reduced through a $2 \mathrm{e}^{-}$pathway in acidic electrolyte to produce $\mathrm{H}_{2} \mathrm{O}_{2}$, catalyzing by $\mathrm{N}$-doped carbon material. ${ }^{[44-45]}$ Based on this, the preliminary mechanism was inferred that NCNC catalyzed AA to dehydrogenize; meanwhile, $\mathrm{O}_{2}$ was catalyzed reduction by accepting $2 \mathrm{e}^{-}$to $\mathrm{H}_{2} \mathrm{O}_{2}$, which similar to the electrocatalytic oxygen reduction reaction (ORR). Nonetheless, more comprehensive understanding in the molecular level is still needed in the future.

The Prussian Blue nanoparticles (PB NPs) were synthesized via reducing the mixture of ferricyanide and ferric ions by hydrogen peroxide. ${ }^{[46]}$ The TEM and SEM images in Figure 2b and S4 showed the uniform distribution of PB nanoparticles with an average size of ca. $10 \mathrm{~nm}$. As shown in Figure S5a, the XRD pattern of PB NPs showed the cubic group $F m 3 m$ diffraction peaks of $2 \theta$ at $24.7^{\circ}, 35.4^{\circ}, 39.7^{\circ}$, and $43.4^{\circ}$, corresponding to 200,220,400,420, and 422 planes, which was perfectly consistent with the record of PB in the JCPDS database (1-0239). ${ }^{[47]}$ Moreover, the UV-Vis spectrum of PB NPs in Figure S5b showed absorption peak around 700 nm, a typical intermetal charge transfer from $\mathrm{Fe}^{2+}$ to $\mathrm{Fe}^{3+}$ in the framework, further proved the successful synthesis of PB. ${ }^{[48]}$ The peroxidase-like activity of PB NPs was investigated by the oxidation of TMB in the presence $\mathrm{H}_{2} \mathrm{O}_{2}$, as prior works. As illustrated in Figure 2e, the distinct absorbance at $652 \mathrm{~nm}$ attributed to $\mathrm{TMB}_{\mathrm{ox}}$ was observed. Moreover, the absorption intensity of $\mathrm{TMB}_{\mathrm{ox}}$ was linearly associated with the concentration of $\mathrm{H}_{2} \mathrm{O}_{2}$ (Figure S6). Thus, PB NPs had a prominent peroxidase-like property, i.e. accelerating the electron-exchange from the TMB donor to the $\mathrm{H}_{2} \mathrm{O}_{2}$ acceptor, in which the reversible conversion of $\mathrm{Fe}^{3+} / \mathrm{Fe}^{2+}$ redox couple was supposed to play an important role. ${ }^{[46]}$

Multitudinous metabolic reactions orderly proceed with the participation of a variety of cascade enzymes. The intermediates would be screened at each metabolic reaction gradually, achieving the high-selectivity of the whole reaction system. 
Interestingly, when NCNC and PB NPs were coupled, the as-obtained cascade reaction system showed the similar reaction mechanism. As shown in Figure 3a, NCNC catalyzed the oxidation of AA, generating $\mathrm{AA}_{\mathrm{ox}}$ and $\mathrm{H}_{2} \mathrm{O}_{2}$. Then, $\mathrm{H}_{2} \mathrm{O}_{2}$ was screened to oxidize TMB as the co-substrate under the catalyzing by PB NPs, in which, AA ox had no evident interferences (More discussion see Supporting Information and Figure S7). However, no $\mathrm{TMB}_{\mathrm{ox}}$ was produced when another common antioxidant Dithiothreitol (DTT) was used the electron donor substrate under the same conditions. Control experiments demonstrated that NCNC also catalyzed the oxidation of DTT, but the molecular oxygen substrate was converted into water (Figure S8 and S10). In this circumstance, neither $\mathrm{DTT}_{\mathrm{ox}}$ or water products was able to triggering the posterior TMB oxidation reaction (Figure 3a). The third representative antioxidant dopamine (DA) was also used to evaluate the cascade nanozymes of NCNC-PB NPs. It was observed that NCNC could not catalyzed the oxidation of DA at all, thus $\mathrm{TMB}_{\mathrm{ox}}$ was hardly generated in the final reaction (Figure 3a, S9 and S10). As a result, the overwhelming amount of the final $\mathrm{TMB}_{\text {ox }}$ product was produced when AA was used as the substrate, compared to DTT and DA (Figure 3b), indicating an improved selectivity of the cascade NCNC-PB NPs with respect to single NCNC.

(a)

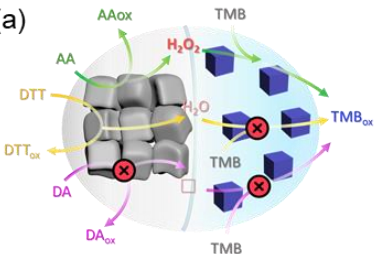

(b)

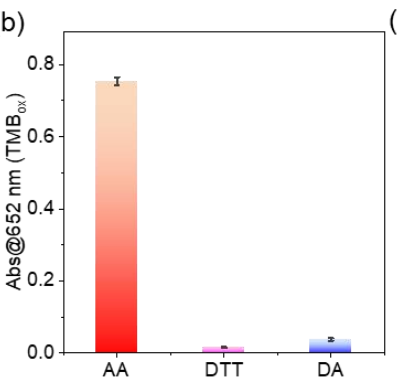

(c)

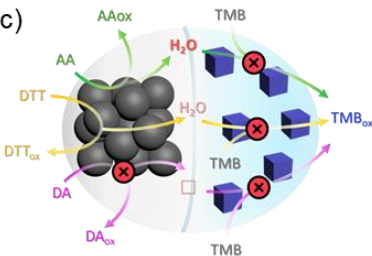

(d)

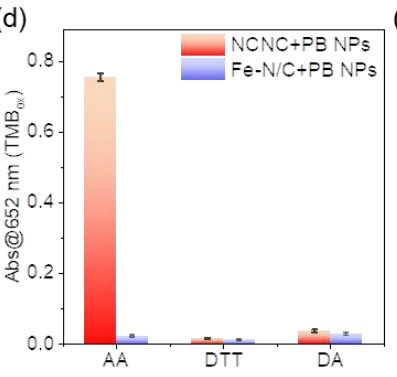

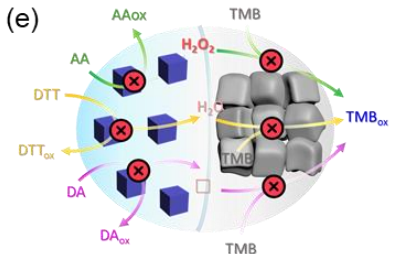

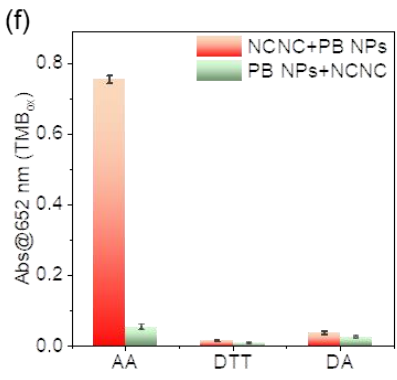

Figure 3. Scheme (a) and absorbance (b) of $\mathrm{TMB}_{\text {ox }}$ (AA, DTT, and DA was catalyzed oxidation by NCNC, TMB was catalyzed oxidation by PB NPs). Scheme (c) and absorbance (d) of $\mathrm{TMB}_{\text {ox }}$ (AA, DTT, and DA was catalyzed oxidation by Fe-N/C, TMB was catalyzed oxidation by PB NPs). Scheme (e) and absorbance (f) of TMB ox (AA, DTT, and DA was catalyzed oxidation by PB NPs, TMB was catalyzed oxidation by NCNC). 
In principle, two important factors were supposed to determine the high selectivity in the cascade reactions, i.e. the rational choice of nanozymes with appropriate catalytic properties and the engineered sequence of nanozymes. To support this assumption, another emerging oxidase-like nanozyme, i.e. Fe-N/C was used to replace NCNC in the cascade reactions (Figure 3c). Different to NCNC, Fe-N/C catalyzed the oxidation of AA into $\mathrm{AA}_{\mathrm{ox}}$ but without the generation of $\mathrm{H}_{2} \mathrm{O}_{2}$ (Figure S11). This process was similar to the $4 \mathrm{e}^{-}$pathway of electrocatalytic ORR by Fe-N/C, $\mathrm{O}_{2}$ was reduced to $\mathrm{H}_{2} \mathrm{O} .{ }^{[49]}$ Accordingly, as shown in Figure 3d, the final $\mathrm{TMB}_{\mathrm{ox}}$ production was negligibly detected after the second nanozymatic reaction. Likewise, the oxidation DTT and DA was also readily catalyzed by $\mathrm{Fe}-\mathrm{N} / \mathrm{C}$, and molecular oxygen underwent a 4-eletron reduction generating no $\mathrm{H}_{2} \mathrm{O}_{2}$, so did $\mathrm{TMB}_{\text {ox. }}$. It demonstrated that $\mathrm{NCNC}$ and $\mathrm{Fe}-\mathrm{N} / \mathrm{C}$ adopted different kinetic pathways for the catalytic oxidation of AA, DTT, and DA. From the structural view of point, Fe-N/C had a unique Fe- $\mathrm{N}_{\mathrm{x}}$ moieties that was very similar to heme cofactor in cytochrome $\mathrm{P} 450$, thus was supposed to provide a stronger molecular oxygen activation during the oxidase-mimicking reaction. ${ }^{[50]}$ In this sense, the balanced activity of NCNC in catalyzation of these antioxidants, endowing it as the most feasible nanozyme for the development of cascade reactions in effectively and selectively transforming the specific molecule into the final target one. On the other hand, an engineered sequence of nanozymes was also important for the successful cascade reactions. It was found that when the sequence of NCNC and PB NPs was exchanged, almost no $\mathrm{TMB}_{\mathrm{ox}}$ was observed, regardless of whether the substrate was AA, DTT or DA (Figure 3e\&3f). Therefore, the high selectivity of the ingenious dualnanozyme cascade strongly relied on both the rational selection of nanozymes with appropriate catalytic properties and the engineered sequence of nanozymes. 
(a)

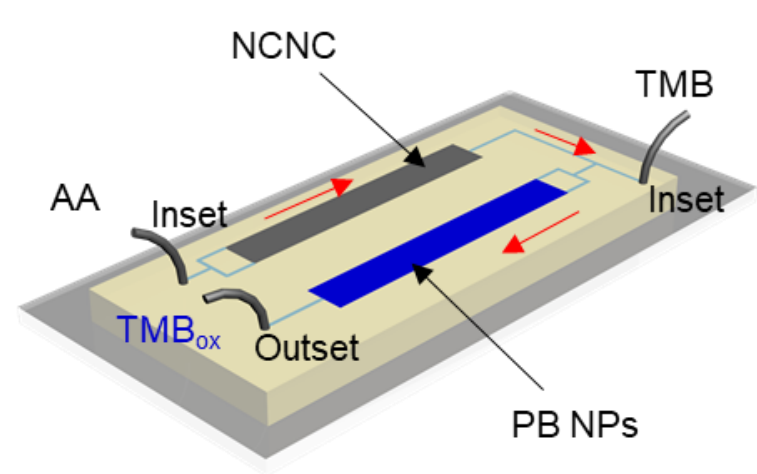

(b)

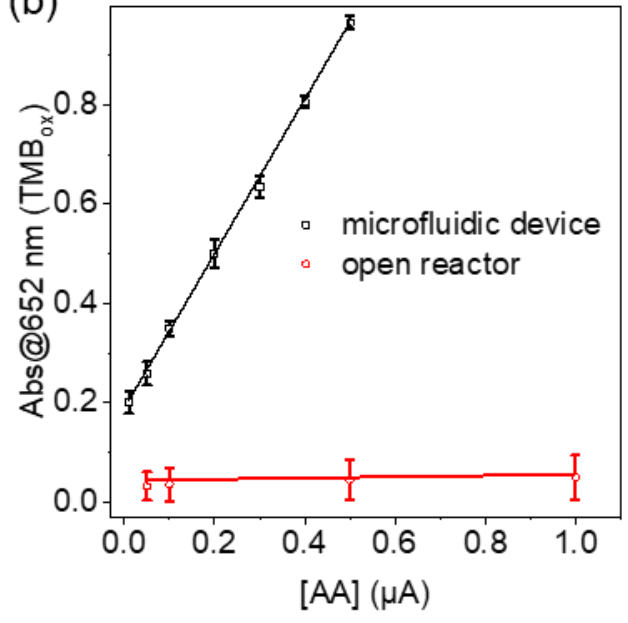

Figure 4. The scheme (a) and the calibration curves (b) of detecting different concentration AA in microfluidic device or open reactor.

The natural enzyme-catalyzed cascades reaction of organisms usually occurs in the confined spaces, preventing the potential loss/conversion of the intermediate species via futile diffusion into the ambient medium, meanwhile promoting the mass transfer. Moreover, a flowing reactor would greatly eliminate the possible inference between substrates and products of each nanozyme. For this, a showcase microfluidic device was fabricated by respectively painting NCNC and PB NPs on the different channels of PDMS, followed by covering a smooth glass to form a confined flow channel (Figure 4a). The AA was catalytically oxidized by NCNC in the first channel, and PB NPs catalyzed the TMB oxidation to blue $\mathrm{TMB}_{\mathrm{ox}}$ with the in-situ generated $\mathrm{H}_{2} \mathrm{O}_{2}$ in the second channel. The solution in the second channel quickly turned blue, which was quantitatively analyzed using the absorbance at $652 \mathrm{~nm}$ of $\mathrm{TMB}_{\mathrm{ox}}$. Compared with the dual nanozyme cascade reaction in an open reactor (Figure S12), the microfluidic device exhibited a superior sensitivity at low concentrations of AA. As displayed in Figure $\mathbf{4 b}$, the absorbance of $\mathrm{TMB}_{\text {ox }}$ response linearly increased with increasing the concentrations of $\mathrm{AA}$ in the range of $10 \mathrm{nM}-500 \mathrm{nM}$, with a detection limit of $1.32 \mathrm{nM}$, which was significantly lower than that of open reactor. The corresponding regression equation could be expressed as $\mathrm{A}_{1}=1.55[\mathrm{AA}]+0.18$, with the correlation coefficient of $\mathrm{R}^{2}=0.999$. However, the regression equation was $\mathrm{A}_{2}=$ $0.014[\mathrm{AA}]+0.045$ with a correlation coefficient of $\mathrm{R}^{2}=0.968$, in the range of $50 \mathrm{nM}$ - 
$1000 \mathrm{nM}$ using the open reactor. Obviously, the dual nanozyme cascade reaction in microfluidic device possessed the higher slope up to 110 times than that of open reactor during the low concentration detection range. In this case, AA with the same concentration can produce higher absorbance of $\mathrm{TMB}_{\mathrm{ox}}$ when the dual nanozyme cascade reaction in microfluidic device rather than open reactor, thanks to the confined effect improving the sensitivity. Furthermore, the proposed dual nanozymes cascade reaction method showed superior LOD compared with previous single nanozyme method via colorimetry (Table S1). ${ }^{[51-55]}$ The nanozymes and substrates in confined space not only reduced the consumption of $\mathrm{H}_{2} \mathrm{O}_{2}$, but also accelerated the mass transfer, which effectively improved the sensitivity of the cascade reaction in microfluidic device.

\section{Conclusions}

In summary, we propose a multiple-nanozyme system with highly selective biocatalytic activity via cascade reaction in a confined space. The ingenious cascade reaction was constructed via rational choosing nanozymes with appropriate catalytic properties and engineering of a particular sequence. The improved selectivity of allnanozyme-system was ascribed to the screening of the products of the prior nanozymatic reaction as the reactants for the afterwards nanozymatic reaction. Moreover, the confined effect not only reduced the consumption of intermediate, but also accelerated the mass transfer, so that the sensitivity of the cascade reaction was also effectively enhanced. As an example, the nanozyme system of NCNC and PB NPs demonstrated excellent selectivity in monitoring of ascorbic acid against other interferant antioxidants. Biomimicking the ingenuity of metabolism of livings to build cascade reaction in confined spaced would provide a new strategy to achieve highselectivity and high-sensitivity of all-nanozyme-system for more prospective applications. 


\section{Acknowledgements}

This work was supported by the National Natural Science Foundation of China (21775018, 21675022), the Natural Science Foundation of Jiangsu Province (BK20170084), the Open Funds of the State Key Laboratory of Electroanalytical Chemistry (SKLEAC201909), and the Fundamental Research Funds for the Central Universities.

\section{Reference}

(1) Klein, W. P.; Thomsen, R. P.; Turner, K. B.; Walper, S. A.; Vranish, J.; Kjems, J.; Ancona, M. G.; Medintz, I. L. Enhanced Catalysis from Multienzyme Cascades Assembled on a DNA Origami Triangle. Acs Nano 2019, 13, 13677-13689.

(2) Chen, W.-H.; Vázquez-González, M.; Zoabi, A.; Abu-Reziq, R.; Willner, I. Biocatalytic cascades driven by enzymes encapsulated in metal-organic framework nanoparticles. Nat. Catal. 2018, 1, 689695 .

(3) Lu, J.; Zhang, Y.; Li, H.; Yu, J.; Liu, S. Electrochemically driven drug metabolism via a CYP1A2UGT1A10 bienzyme confined in a graphene nano-cage. Chem. Commun. 2014, 50, 13896-13899.

(4) Chen, R. P.; Blackstock, D.; Sun, Q.; Chen, W. Dynamic protein assembly by programmable DNA strand displacement. Nat. Chem. 2018, 10, 474-481.

(5) Raeeszadeh-Sarmazdeh, M.; Hartzell, E.; Price, J. V.; Chen, W. Protein nanoparticles as multifunctional biocatalysts and health assessment sensors. Curr. Opin. Chem. Eng. 2016, 13, 109-118.

(6) Huang, Y. Y.; Ren, J. S.; Qu, X. G. Nanozymes: Classification, Catalytic Mechanisms, Activity Regulation, and Applications. Chem. Rev. 2019, 119, 4357-4412.

(7) Sun, H. J.; Zhou, Y.; Ren, J. S.; Qu, X. G. Carbon Nanozymes: Enzymatic Properties, Catalytic Mechanism, and Applications. Angew. Chem. Int. Ed. 2018, 57, 9224-9237.

(8) Wang, X. Y.; Hu, Y. H.; Wei, H. Nanozymes in bionanotechnology: from sensing to therapeutics and beyond. Inorg. Chem. Front. 2016, 3, 41-60.

(9) Gao, L. Z.; Zhuang, J.; Nie, L.; Zhang, J. B.; Zhang, Y.; Gu, N.; Wang, T. H.; Feng, J.; Yang, D. L.; Perrett, S.; Yan, X. Intrinsic peroxidase-like activity of ferromagnetic nanoparticles. Nat. Nanotech. 2007, 2, 577-583.

(10) Zheng, X. X.; Liu, Q.; Jing, C.; Li, Y.; Li, D.; Luo, W. J.; Wen, Y. Q.; He, Y.; Huang, Q.; Long, Y. T.; Fan, C. H. Catalytic Gold Nanoparticles for Nanoplasmonic Detection of DNA Hybridization. Angew. Chem. Int. Ed. 2011, 50, 11994-11998.

(11) Hu, Y. H.; Cheng, H. J.; Zhao, X. Z.; Wu, J. J.; Muhammad, F.; Lin, S. C.; He, J.; Zhou, L. Q.; Zhang, C. P.; Deng, Y.; Wang, P.; Zhou, Z. Y.; Nie, S. M.; Wei, H. Surface-Enhanced Raman Scattering Active Gold Nanoparticles with Enzyme-Mimicking Activities for Measuring Glucose and Lactate in Living Tissues. ACS Nano 2017, 11, 5558-5566.

(12) Luo, W. J.; Zhu, C. F.; Su, S.; Li, D.; He, Y.; Huang, Q.; Fan, C. H. Self-Catalyzed, Self-Limiting Growth of Glucose Oxidase-Mimicking Gold Nanoparticles. ACS Nano 2010, 4, 7451-7458.

(13) Karakoti, A. S.; Singh, S.; Kumar, A.; Malinska, M.; Kuchibhatla, S.; Wozniak, K.; Self, W. T.; Seal, S. PEGylated Nanoceria as Radical Scavenger with Tunable Redox Chemistry. J. Am. Chem. Soc. 2009, $131,14144-14145$. 
(14) Li, Y. Y.; He, X.; Yin, J. J.; Ma, Y. H.; Zhang, P.; Li, J. Y.; Ding, Y. Y.; Zhang, J.; Zhao, Y. L.; Chai, Z. F.; Zhang, Z. Y. Acquired Superoxide-Scavenging Ability of Ceria Nanoparticles. Angew. Chem. Int. Ed. 2015, 54, 1832-1835.

(15) Kim, C. K.; Kim, T.; Choi, I. Y.; Soh, M.; Kim, D.; Kim, Y. J.; Jang, H.; Yang, H. S.; Kim, J. Y.; Park, H. K.; Park, S. P.; Park, S.; Yu, T.; Yoon, B. W.; Lee, S. H.; Hyeon, T. Ceria Nanoparticles that can Protect against Ischemic Stroke. Angew. Chem. Int. Ed. 2012, 51, 11039-11043.

(16) Huang, Y. Y.; Liu, Z.; Liu, C. Q.; Ju, E. G.; Zhang, Y.; Ren, J. S.; Qu, X. G. Self-Assembly of Multinanozymes to Mimic an Intracellular Antioxidant Defense System. Angew. Chem. Int. Ed. 2016, 55, 6646-6650.

(17) Pogacean, F.; Socaci, C.; Pruneanu, S.; Biris, A. R.; Coros, M.; Magerusan, L.; Katona, G.; Turcu, R.; Borodi, G. Graphene based nanomaterials as chemical sensors for hydrogen peroxide - A comparison study of their intrinsic peroxidase catalytic behavior. Sensor Actuat. B-chem 2015, 213, 474-483.

(18) Lin, Y. H.; Ren, J. S.; Qu, X. G. Catalytically Active Nanomaterials: A Promising Candidate for Artificial Enzymes. Accounts of Chemical Research 2014, 47, 1097-1105.

(19) Kuah, E.; Toh, S.; Yee, J.; Ma, Q.; Gao, Z. Q. Enzyme Mimics: Advances and Applications. Chem.Eur. J. 2016, 22, 8404-8430.

(20) Garg, B.; Bisht, T.; Ling, Y. C. Graphene-Based Nanomaterials as Efficient Peroxidase Mimetic Catalysts for Biosensing Applications: An Overview. Molecules 2015, 20, 14155-14190.

(21) Mancin, F.; Prins, L. J.; Pengo, P.; Pasquato, L.; Tecilla, P.; Scrimin, P. Hydrolytic MetalloNanozymes: From Micelles and Vesicles to Gold Nanoparticles. Molecules 2016, 21, 1014.

(22) Garg, B.; Bisht, T. Carbon Nanodots as Peroxidase Nanozymes for Biosensing. Molecules 2016, 21, 1653 .

(23) Song, Y. J.; Wang, X. H.; Zhao, C.; Qu, K. G.; Ren, J. S.; Qu, X. G. Label-Free Colorimetric Detection of Single Nucleotide Polymorphism by Using Single-Walled Carbon Nanotube Intrinsic Peroxidase-Like Activity. Chem.-Eur. J. 2010, 16, 3617-3621.

(24) Cui, R. J.; Han, Z. D.; Zhu, J. J. Helical Carbon Nanotubes: Intrinsic Peroxidase Catalytic Activity and Its Application for Biocatalysis and Biosensing. Chem.-Eur. J. 2011, 17, 9377-9384.

(25) Qu, F. L.; Li, T.; Yang, M. H. Colorimetric platform for visual detection of cancer biomarker based on intrinsic peroxidase activity of graphene oxide. Biosens. Bioelectron. 2011, 26, 3927-3931.

(26) Shi, W. B.; Wang, Q. L.; Long, Y. J.; Cheng, Z. L.; Chen, S. H.; Zheng, H. Z.; Huang, Y. M. Carbon nanodots as peroxidase mimetics and their applications to glucose detection. Chem. Commun. 2011, 47, 6695-6697.

(27) Wang, X. H.; Qu, K. G.; Xu, B. L.; Ren, J. S.; Qu, X. G. Multicolor luminescent carbon nanoparticles: Synthesis, supramolecular assembly with porphyrin, intrinsic peroxidase-like catalytic activity and applications. Nano. Res. 2011, 4, 908-920.

(28) Zhang, Z. J.; Zhang, X. H.; Liu, B. W.; Liu, J. W. Molecular Imprinting on Inorganic Nanozymes for Hundred-fold Enzyme Specificity. J. Am. Chem. Soc. 2017, 139, 5412-5419.

(29) Zhang, Z. J.; Liu, B. W.; Liu, J. W. Molecular Imprinting for Substrate Selectivity and Enhanced Activity of Enzyme Mimics. Small 2017, 13.

(30) Wang, Q.; Zhang, X.; Huang, L.; Zhang, Z.; Dong, S. GOx@ZIF-8(NiPd) Nanoflower: An Artificial Enzyme System for Tandem Catalysis. Angew. Chem. Int. Ed. 2017, 56, 16082-16085.

(31) Cao, W.; Lin, J. S.; Muhammad, F.; Wang, Q.; Wang, X. Y.; Lou, Z. P.; Wei, H. Porous Ruthenium Selenide Nanoparticle as a Peroxidase Mimic for Glucose Bioassay. J. Anal. Test. 2019, 3, 253-259.

(32) Cheng, H. J.; Wang, X. Y.; Wei, H. Ratiometric Electrochemical Sensor for Effective and Reliable 
Detection of Ascorbic Acid in Living Brains. Anal. Chem. 2015, 87, 8889-8895.

(33) Teschke, R. Alcoholic Liver Disease: Alcohol Metabolism, Cascade of Molecular Mechanisms, Cellular Targets, and Clinical Aspects. Biomedicines 2018, 6, 106.

(34) Kapur, B. M.; Vandenbroucke, A. C.; Adamchik, Y.; Lehotay, D. C.; Carlen, P. L. Formic acid, a novel metabolite of chronic ethanol abuse, causes neurotoxicity, which is prevented by folic acid. Alcohol. Clin. Exp. Res 2007, 31, 2114-2120.

(35) Smeets, V.; Baaziz, W.; Ersen, O.; Gaigneaux, E. M.; Boissiere, C.; Sanchez, C.; Debecker, D. P. Hollow zeolite microspheres as a nest for enzymes: a new route to hybrid heterogeneous catalysts. Chem. Sci. 2020, 11, 954-961.

(36) Xiao, J. D.; Han, L. L.; Luo, J.; Yu, S. H.; Jiang, H. L. Integration of Plasmonic Effects and Schottky Junctions into Metal-Organic Framework Composites: Steering Charge Flow for Enhanced Visible-Light Photocatalysis. Angew. Chem. Int. Ed. 2018, 57, 1103-1107.

(37) Parlett, C. M. A.; Isaacs, M. A.; Beaumont, S. K.; Bingham, L. M.; Hondow, N. S.; Wilson, K.; Lee, A. F. Spatially orthogonal chemical functionalization of a hierarchical pore network for catalytic cascade reactions. Nat. Mater. 2016, 15, 178-182.

(38) Lu, J. S.; Zhang, Y. J.; Li, H. N.; Yu, J. C.; Liu, S. Q. Electrochemically driven drug metabolism via a CYP1A2-UGT1A10 bienzyme confined in a graphene nano-cage. Chem. Commun. 2014, 50, 1389613899.

(39) Lu, J. S.; Shen, Y. F.; Liu, S. Q. Enhanced light-driven catalytic performance of cytochrome P450 confined in macroporous silica. Chem. Commun. 2016, 52, 7703-7706.

(40) Zhao, J.; Lai, H. W.; Lyu, Z. Y.; Jiang, Y. F.; Xie, K.; Wang, X. Z.; Wu, Q.; Yang, L. J.; Jin, Z.; Ma, Y. W.; Liu, J.; Hu, Z. Hydrophilic Hierarchical Nitrogen-Doped Carbon Nanocages for Ultrahigh Supercapacitive Performance. Adv. Mat. 2015, 27, 3541-3545.

(41) Chen, S.; Bi, J.; Zhao, Y.; Yang, L.; Zhang, C.; Ma, Y.; Wu, Q.; Wang, X.; Hu, Z. Nitrogen-doped carbon nanocages as efficient metal-free electrocatalysts for oxygen reduction reaction. Adv. Mat. 2012, 24, 5593-5597, 5646.

(42) Jiang, L.; Wang, K.; Zhang, F.; Zhang, Y.; Wang, H.; Liu, S. Enhanced Metabolic Activity of Cytochrome P450 via Carbon Nanocage-Based Photochemical Bionanoreactor. ACS Appl. Mater. Inter. 2018, 10, 41956-41961.

(43) Huang, Y.; Zhao, M. T.; Han, S. K.; Lai, Z. C.; Yang, J.; Tan, C. L.; Ma, Q. L.; Lu, Q. P.; Chen, J. Z.; Zhang, X.; Zhang, Z. C.; Li, B.; Chen, B.; Zong, Y.; Zhang, H. Growth of Au Nanoparticles on 2D Metalloporphyrinic Metal-Organic Framework Nanosheets Used as Biomimetic Catalysts for Cascade Reactions. Adv. Mat. 2017, 29, 1700102.

(44) Noffke, B. W.; Li, Q.; Raghavachari, K.; Li, L.-s. A Model for the pH-Dependent Selectivity of the Oxygen Reduction Reaction Electrocatalyzed by N-Doped Graphitic Carbon. J. Am. Chem. Soc. 2016, 138, 13923-13929.

(45) Masa, J.; Xia, W.; Muhler, M.; Schuhmann, W. On the Role of Metals in Nitrogen-Doped Carbon Electrocatalysts for Oxygen Reduction. Angew. Chem. Int. Ed. 2015, 54, 10102-10120.

(46) Komkova, M. A.; Karyakina, E. E.; Karyakin, A. A. Catalytically Synthesized Prussian Blue Nanoparticles Defeating Natural Enzyme Peroxidase. J. Am. Chem. Soc. 2018, 140, 11302-11307.

(47) Zhang, Y. J.; Wen, Y.; Liu, Y.; Li, D.; Li, J. H. Functionalization of single-walled carbon nanotubes with Prussian blue. Electrochem. Commun. 2004, 6, 1180-1184.

(48) Zhang, W. M.; Ma, D.; Du, J. X. Prussian blue nanoparticles as peroxidase mimetics for sensitive colorimetric detection of hydrogen peroxide and glucose. Talanta 2014, 120, 362-367. 
(49) Chung, H. T.; Cullen, D. A.; Higgins, D.; Sneed, B. T.; Holby, E. F.; More, K. L.; Zelenay, P. Direct atomic-level insight into the active sites of a high-performance PGM-free ORR catalyst. Science 2017, 357, 479-483.

(50) He, F.; Mi, L.; Shen, Y. F.; Mori, T.; Liu, S. Q.; Zhang, Y. J. Fe-N-C Artificial Enzyme: Activation of Oxygen for Dehydrogenation and Monoxygenation of Organic Substrates under Mild Condition and Cancer Therapeutic Application. ACS Appl. Mater. Inter. 2018, 10, 35327-35333.

(51) Fang, X.; Wang, J.; Cui, X. Q.; Zhang, Y. H.; Zhu, R. F.; Zhao, H.; Li, Z. X. Sensitive and facile colorimetric sensing strategy for ascorbic acid determination based on $\mathrm{CoOOH}$ nanoflakes-ABTs oxidative system. Colloid. Surface. A 2019, 575, 66-74.

(52) Chi, M. Q.; Zhu, Y.; Jing, L. W.; Wang, C.; Lu, X. F. Fabrication of oxidase-like polyaniline-MnO2 hybrid nanowires and their sensitive colorimetric detection of sulfite and ascorbic acid. Talanta 2019, 191, 171-179.

(53) Guan, H. N.; Han, B. L.; Gong, D. Z.; Song, Y.; Liu, B.; Zhang, N. Colorimetric sensing for ascorbic acid based on peroxidase-like of GoldMag nanocomposites. Spectrochim. Acta. A 2019, $222,9$.

(54) Fan, S. S.; Zhao, M. G.; Ding, L. J.; Li, H.; Chen, S. G. Preparation of Co3O4/crumpled graphene microsphere as peroxidase mimetic for colorimetric assay of ascorbic acid. Biosens. Bioelectron. 2017, 89, 846-852.

(55) Zhang, J. W.; Zhang, H. T.; Du, Z. Y.; Wang, X. Q.; Yua, S. H.; Jiang, H. L. Water-stable metalorganic frameworks with intrinsic peroxidase-like catalytic activity as a colorimetric biosensing platform. Chem. Commun. 2014, 50, 1092-1094. 
Supporting Information

\section{Endowing Nanozymes High Biocatalytic Selectivity by Substrates Channeling and Screening}

Qing Zhou, Hong Yang, Xinghua Chen, Yuan Xu, Dan Han, Sisi Zhou, Songqin Liu, Yanfei Shen, Yuanjian Zhang*

Jiangsu Engineering Laboratory of Smart Carbon-Rich Materials and Device, Jiangsu Province Hi-Tech Key Laboratory for Bio-Medical Research, School of Chemistry and Chemical Engineering, Medical School, Southeast University, Nanjing 211189, China. E-mail: Yuanjian.Zhang@seu.edu.cn 


\section{Experimental Section}

\section{Materials and Reagents}

Nitrogen-doped carbon nanocages (NCNC), Prussian blue nanoparticles (PB NPs), iron-nitrogen-carbon $(\mathrm{Fe}-\mathrm{N} / \mathrm{C})$ were prepared by following the previous works. ${ }^{\text {S1-3 }}$ The Britton-Robinson (BR) buffer solution was compounded by phosphoric acid, acetic acid, boric acid, and sodium hydroxide, following the previous report. ${ }^{\mathrm{S} 4} 3,3^{\prime}, 5,5^{\prime}$ Tetramethylbenzidine (TMB), peroxidase from horseradish (HRP), aniline, cyanamide, DL-Dithiothreitol (DTT), Dopamine (DA) were obtained from Sigma-Aldrich. Ascorbic acid (AA), potassium ferricyanide, potassium ferrocyanide, potassium chloride, hydrochloric Acid, $\mathrm{H}_{2} \mathrm{O}_{2}(30 \%)$, pyridine, phosphoric acid, acetic acid, boric acid, and sodium hydroxide, and ethanol were purchased from Sinopharm Chemical Reagent Co., Ltd. (Shanghai, China). All other reagents were of analytical grade and used as received unless otherwise specified. Ultrapure water $(18.2 \mathrm{M} \Omega \mathrm{cm})$ from a Smart2 Pure water purification system (Thermo Fisher).

\section{Apparatus}

The transmission electron microscopy (TEM) images were collected by transmission electron microscopy (JEM-2100f, JEOL, Japan). The scanning electron microscopy (SEM) images were obtained from a Zeiss Ultra Plus (German). The UVvis absorption spectra were measured using the Cary100 UV-vis spectrophotometer (Agilent, Singapore). The powder X-ray diffractometer (XRD) was collected by an Ultima IV X-ray diffractometer (Rigaku, Japan). The electrospray ionization mass spectra (ESI-MS) were measured by a liquid phase high resolution time-of flight mass spectrometer (Agilent, Singapore).

\section{Preparation of Nanozymes}

The Prussian blue nanoparticles (PB NPs) were prepared based on the previous report. Briefly, the $\mathrm{FeCl}_{3}(25 \mathrm{mM}), \mathrm{K}_{3}\left[\mathrm{Fe}(\mathrm{CN})_{6}\right](25 \mathrm{mM})$ and $\mathrm{KCl}(0.1 \mathrm{M})$ were dissolved in $20 \mathrm{~mL}$ of $0.1 \mathrm{M} \mathrm{HCl}$ solution in $50 \mathrm{~mL}$ round-bottom flask. Followed vigorous stirring, $50 \mu \mathrm{L} 30 \% \mathrm{H}_{2} \mathrm{O}_{2}$ was dropped gradually into the mixture. After 30 min, the dark blue PB NPs were collected by centrifugation (13000 rpm, $10 \mathrm{~min}$ ), and washed with $0.1 \mathrm{M} \mathrm{KCl} / 0.1 \mathrm{M} \mathrm{HCl}$ solution. The precipitate of PB NPs was dried at $80{ }^{\circ} \mathrm{C}$ for $12 \mathrm{~h}$ in a vacuum drier. Then, obtained PB NPs was dissolved in ultrapure 
water for $1 \mathrm{mg} / \mathrm{mL}$ aqueous solution, and stored under darkness.

The nitrogen-doped carbon nanocages $(\mathrm{NCNC})$ were prepared via the $\mathrm{MgO}$ template method with pyridine as the precursor at $800{ }^{\circ} \mathrm{C} .1 \mathrm{mg} \mathrm{NCNC}$ was dispersed in $1 \mathrm{~mL}$ water containing $2 \%$ ethanol. The obtained NCNC solution was stored under darkness and were ultrasonicated prior to use.

The iron-nitrogen-carbon (Fe-N/C) was synthesized based on the previous report. Briefly, aniline and cyanamide were dissolved in $1.5 \mathrm{M} \mathrm{HCl}$ solution, followed by adding iron (III) chloride as the iron precursor. Then, the ammonium persulfate was added as an oxidant to catalyze the aniline polymerization, stirring for $4 \mathrm{~h}$ at room temperature to ensure the full polymerization of aniline. Afterwards, pretreated-carbon was mixed with above solution, stirring until it become tar-like at $80^{\circ} \mathrm{C}$. The subsequent heat treatment was performed at $900{ }^{\circ} \mathrm{C}$ in nitrogen atmosphere for $1 \mathrm{~h}$. The obtained product was washed by $0.5 \mathrm{M} \mathrm{H}_{2} \mathrm{SO}_{4}$ and water, after ground to powder. After dried in vacuum oven at $90{ }^{\circ} \mathrm{C}$, the final product was obtained by heat-treated again at $900{ }^{\circ} \mathrm{C}$ in nitrogen atmosphere for $3 \mathrm{~h} .1 \mathrm{mg} \mathrm{Fe}-\mathrm{N} / \mathrm{C}$ was dispersed in $1 \mathrm{~mL}$ water containing $2 \%$ ethanol. The obtained Fe-N/C solution was stored under darkness and were ultrasonicated prior to use.

\section{Catalytic Oxidation of AA by NCNC}

The catalytic oxidation of AA by NCNC was performed via dropping $10 \mu \mathrm{L}$ of NCNC $(1 \mathrm{mg} / \mathrm{mL})$ into $1 \mathrm{~mL}$ Britton-Robinson buffer solution $(\mathrm{pH}=3)$ containing 50 $\mu \mathrm{M}$ AA solution. After the above mixed solution incubated at $35{ }^{\circ} \mathrm{C}$ for $10 \mathrm{~min}$, the NCNC was removed by centrifugation (13000 rpm, $3 \mathrm{~min}$ ). Then, $20 \mu \mathrm{L}$ of $100 \mathrm{mM}$ TMB and $10 \mu \mathrm{L}$ of $1 \mathrm{mg} / \mathrm{mL}$ HRP were added into the supernatants, and the above solution was incubated for $5 \mathrm{~min}$ at $35^{\circ} \mathrm{C}$. Finally, the absorption peak of the TMB oxidation product $\left(\mathrm{TMB}_{\mathrm{ox}}\right)$ at $652 \mathrm{~nm}$ was monitored by a UV-vis spectrophotometer. Furthermore, a conventional colorimetric method was introduced to demonstrate that quantificational $\mathrm{H}_{2} \mathrm{O}_{2}$ was generated during the catalytic oxidation of AA by NCNC. In detail, $10 \mu \mathrm{L}$ of NCNC (1 mg/mL) was added into $1 \mathrm{~mL}$ Britton-Robinson (BR) buffer solution $(\mathrm{pH}=3)$ containing different concentration of AA solution $(1,5,10,20,30$, 40 , and $50 \mu \mathrm{M})$. After incubation of the above mixed solution at $35^{\circ} \mathrm{C}$ for $10 \mathrm{~min}$, the supernatants were collected by centrifugation (13000 rpm, $3 \mathrm{~min}$ ). Then, $20 \mu \mathrm{L}$ of 100 $\mathrm{mM}$ TMB and $10 \mu \mathrm{L}$ of $1 \mathrm{mg} / \mathrm{mL}$ HRP were added into the supernatants and incubated 
for $5 \mathrm{~min}$ at $35{ }^{\circ} \mathrm{C}$. Finally, the generated $\mathrm{H}_{2} \mathrm{O}_{2}$ was estimated by monitoring the absorption intensity of the $\mathrm{TMB}_{\mathrm{ox}}$ at $652 \mathrm{~nm}$ by a UV-vis spectrophotometer.

\section{Catalytic Oxidation of TMB by PB NPs}

The experiments that PB NPs catalyzed oxidation of TMB were performed by adding $10 \mu \mathrm{L}$ of PB NPs $(1 \mathrm{mg} / \mathrm{mL})$ into $1 \mathrm{~mL} \mathrm{BR}$ buffer solution $(\mathrm{pH}=3)$ containing $2 \mathrm{mM}$ TMB and $20 \mu \mathrm{M} \mathrm{H}_{2} \mathrm{O}_{2}$ solution. And then the above mixed solution was incubated at $35{ }^{\circ} \mathrm{C}$ for $30 \mathrm{~min}$. The $\mathrm{TMB}_{\mathrm{ox}}$ was estimated by monitoring the intensity of the absorption peak at $652 \mathrm{~nm}$ using a UV-vis spectrophotometer.

Moreover, the quantitative experiment was carried out to prove that PB NPs could use for quantitative determination of $\mathrm{H}_{2} \mathrm{O}_{2}$. In detail, $10 \mu \mathrm{L}$ of PB NPs $(1 \mathrm{mg} / \mathrm{mL})$ was added into $1 \mathrm{~mL}$ Britton-Robinson (BR) buffer solution $(\mathrm{pH}=3)$ containing $2 \mathrm{mM}$ TMB and various concentration of $\mathrm{H}_{2} \mathrm{O}_{2}$ solution $(2 \sim 24 \mu \mathrm{M})$. After incubation, the absorption intensity at $652 \mathrm{~nm}$ was collected by a UV-vis spectrophotometer.

\section{Fabrication of Dual Nanozyme Cascade Reaction}

A cascade reaction was fabricated using NCNC and PB NPs. Firstly, $10 \mu \mathrm{L}$ of NCNC $(1 \mathrm{mg} / \mathrm{mL})$ was added into the $1 \mathrm{~mL}$ AA solution $(50 \mu \mathrm{M}$ in BR buffer, $\mathrm{pH}=3)$, and the mixed solution was incubated for $10 \mathrm{~min}$ at $35^{\circ} \mathrm{C}$. After centrifugation (10000 rpm, 1min), TMB (20 $\mu \mathrm{L}, 100 \mathrm{mM})$ and PB NPs $(10 \mu \mathrm{L}, 1 \mathrm{mg} / \mathrm{mL})$ were dropped into the obtained supernatant. And then, the above solution was incubated for another 30 $\min$ at $35{ }^{\circ} \mathrm{C}$. Finally, the reaction solution was characterized by the UV-vis spectrophotometer. The control experiment that Fe-N/C was used to replace NCNC, was carried out under the same condition.

In order to engineer the sequence of these nanozymes, NCNC and PB NPs were used to catalyze oxidation of TMB and AA, respectively. Detailed, $10 \mu \mathrm{L}$ of PB NPs (1 $\mathrm{mg} / \mathrm{mL})$ was added into the $1 \mathrm{~mL} \mathrm{AA}$ solution $(50 \mu \mathrm{M}$ in BR buffer, $\mathrm{pH}=3)$ and the above solution was incubated for $10 \mathrm{~min}$ at $35^{\circ} \mathrm{C}$. After centrifugation $(10000 \mathrm{rpm}$, $1 \mathrm{~min}), 10 \mu \mathrm{L}$ of NCNC ( $1 \mathrm{mg} / \mathrm{mL})$ and $20 \mu \mathrm{L}$ of TMB $(100 \mathrm{mM})$ were dropped into the obtained supernatant. Then, the above mixed solution was incubated at $35{ }^{\circ} \mathrm{C}$ for 30 min. Finally, the reaction solution was characterized by the UV-vis spectrophotometer.

\section{Dual Nanozyme Cascade Reaction with Other Substrates}

The fabricated dual nanozyme cascade reaction was also used to catalyzed oxidation of other substrates, such as DTT and DA. Similarly, $10 \mu \mathrm{L}$ of NCNC (1 
$\mathrm{mg} / \mathrm{mL})$ was added into the $1 \mathrm{~mL}$ DTT or DA solution (50 $\mu \mathrm{M}$ in BR buffer, $\mathrm{pH}=3)$, and followed incubated for $10 \mathrm{~min}$ at $35^{\circ} \mathrm{C}$. After centrifugation (10000 rpm, 1min), $20 \mu \mathrm{L}$ of $100 \mathrm{mM}$ TMB and $10 \mu \mathrm{L}$ of $1 \mathrm{mg} / \mathrm{mL}$ PB NPs were dropped into the obtained supernatant, followed incubated for another $30 \mathrm{~min}$ at $35{ }^{\circ} \mathrm{C}$. Finally, the reaction solution was characterized by the UV-vis spectrophotometer.

\section{Detection of AA in Open Reactor}

$10 \mu \mathrm{L}$ of NCNC $(1 \mathrm{mg} / \mathrm{mL})$ was added into the $1 \mathrm{~mL}$ AA solution with different concentrations $(0.05,0.1,0.5,1,5,10,20,30,40,50,60,70 \mu \mathrm{M}$ in BR buffer, $\mathrm{pH}=3)$, and followed incubated for $10 \mathrm{~min}$ at $35{ }^{\circ} \mathrm{C}$. After centrifugation (10000 rpm, 1min), $20 \mu \mathrm{L}$ of $100 \mathrm{mM}$ TMB and $10 \mu \mathrm{L}$ of $1 \mathrm{mg} / \mathrm{mL}$ PB NPs were dropped into the obtained supernatants. And then, the above solutions were incubated for another $30 \mathrm{~min}$ at $35^{\circ} \mathrm{C}$. Finally, the resulting reactive solutions were characterized by the UV-vis spectrophotometer. And the experiment condition of $\mathrm{pH}$, reaction temperature and incubation time were optimized.

\section{Dual nanozyme cascade reaction in microfluidic device}

The microfluidic device was fabricated using poly(dimethylsiloxane) (PDMS) and slide glass, and syringe-pump connected by polypropylene tubing. The nanozymes (NCNC and PB NPs) were immobilized on the PDMS wall, respectively. Firstly, the BR buffer solution containing different concentrations of AA (BR buffer, $\mathrm{pH}=3$ ) was pumped into the first microfluidic reaction channel, retained for 10 mins at $35^{\circ} \mathrm{C}$. Then, the solution was pumped into the next channel, with the TMB pumped from the downstream inlet simultaneously. Finally, the reactive blue solution was collected from the outlet and characterized using the UV-vis spectrophotometer. 


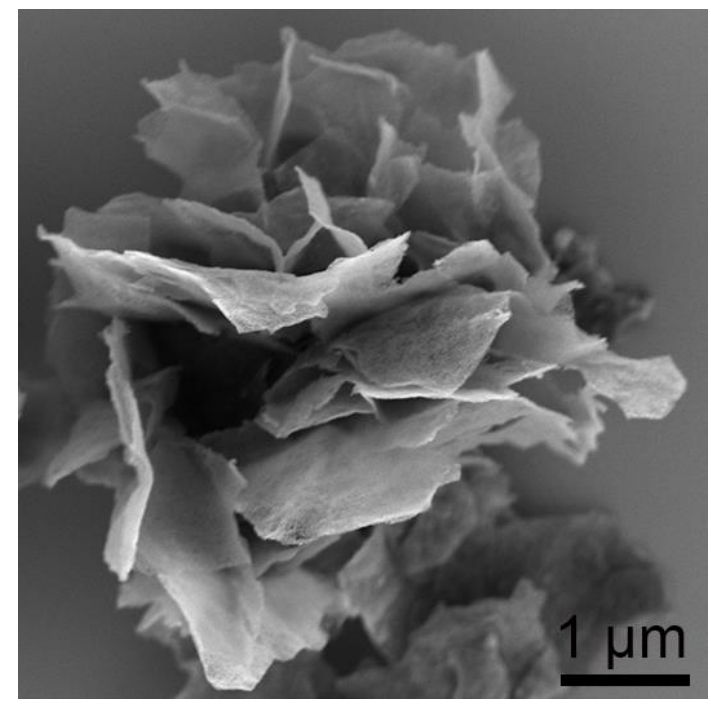

Figure S1. SEM image of NCNC. 

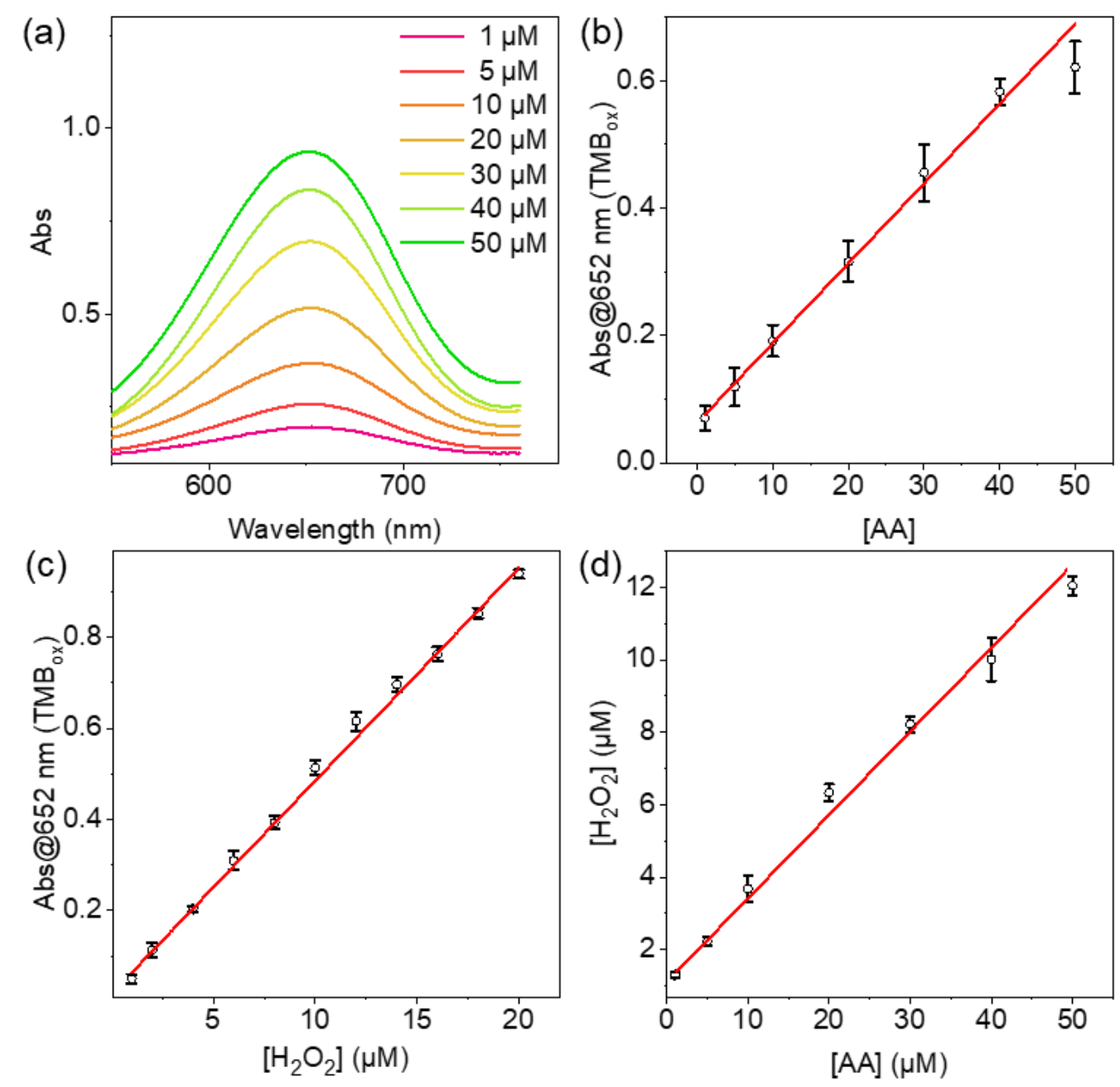

Figure S2. (a) UV-vis spectra of $\mathrm{TMB}_{\text {ox }}$ catalyzed by HRP for evaluating the amount of generated $\mathrm{H}_{2} \mathrm{O}_{2}$ during the catalyzation of AA (1-50 $\mu \mathrm{M}$ ) by NCNC. (b) Calibration curve of the Abs of $\mathrm{TMB}_{\mathrm{ox}}$ with different concentration AA. (c) Standard calibration plot for detection of $\left[\mathrm{H}_{2} \mathrm{O}_{2}\right]$ by the colorimetric TMB-HRP method. (d) Calibration curve of the generated $\mathrm{H}_{2} \mathrm{O}_{2}$ during $\mathrm{NCNC}$ catalyzing oxidation of different concentration of AA (based on Figure S2b and Figure S2c). 

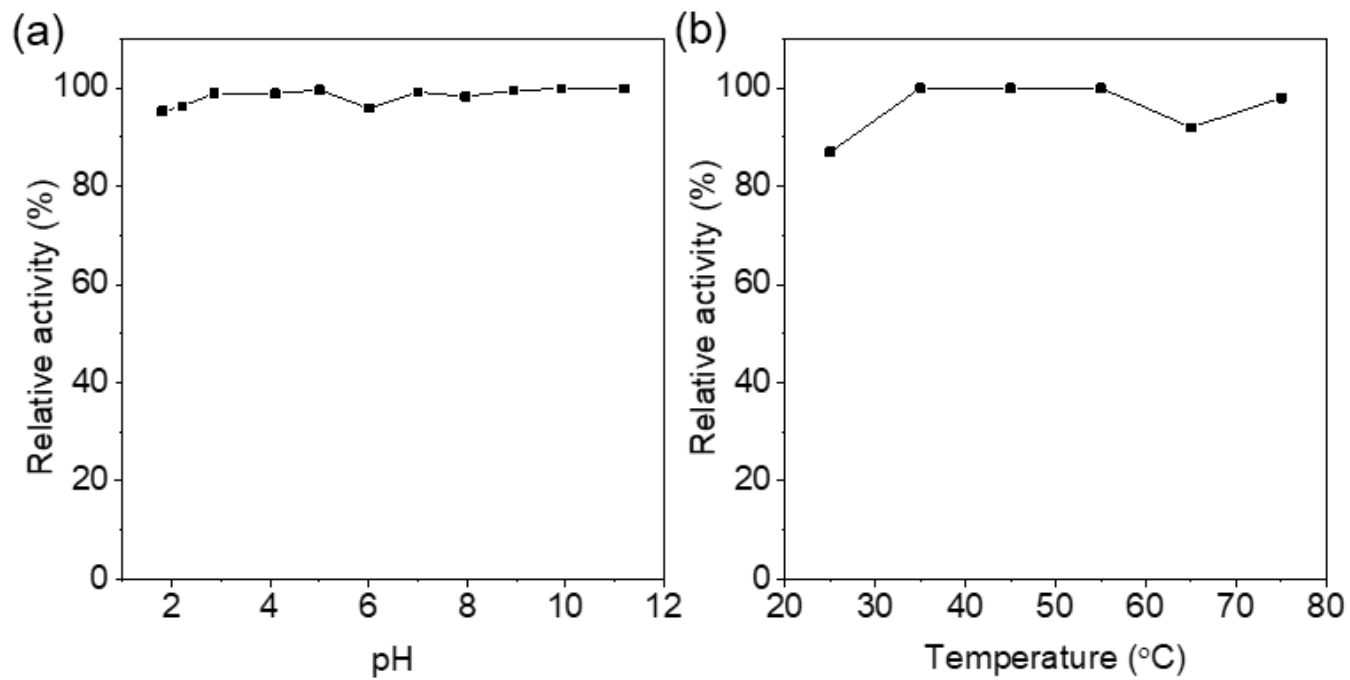

Figure S3. Relative activity of $\mathrm{NCNC}$ after incubated in different $\mathrm{pH}$ (a) and temperature (b).

In order to evaluate the stability in harsh condition, NCNC was incubated in different $\mathrm{pH}$ and temperature for $12 \mathrm{~h}$. After that, $10 \mu \mathrm{L}$ of $1 \mathrm{mg} / \mathrm{mL} \mathrm{NCNC}$ was dropped into $1 \mathrm{mLAA}$ solution $(50 \mu \mathrm{M})$ and incubated for $10 \mathrm{~min}$ at $35^{\circ} \mathrm{C}$. The relative variation of the absorption intensity at $247 \mathrm{~nm}$ was used to indicate the relative activity of NCNC. As shown in Figure S3a, the activity of NCNC kept above 95\% after incubated in different $\mathrm{pH}$. And $\mathrm{NCNC}$ exhibited $88 \%$ of catalytic activity in elevated temperature up to $75^{\circ} \mathrm{C}$ (Figure $\mathrm{S} 3 \mathrm{~b}$ ). Therefore, NCNC showed high stability after a series of $\mathrm{pH}$ and temperature treatments. 


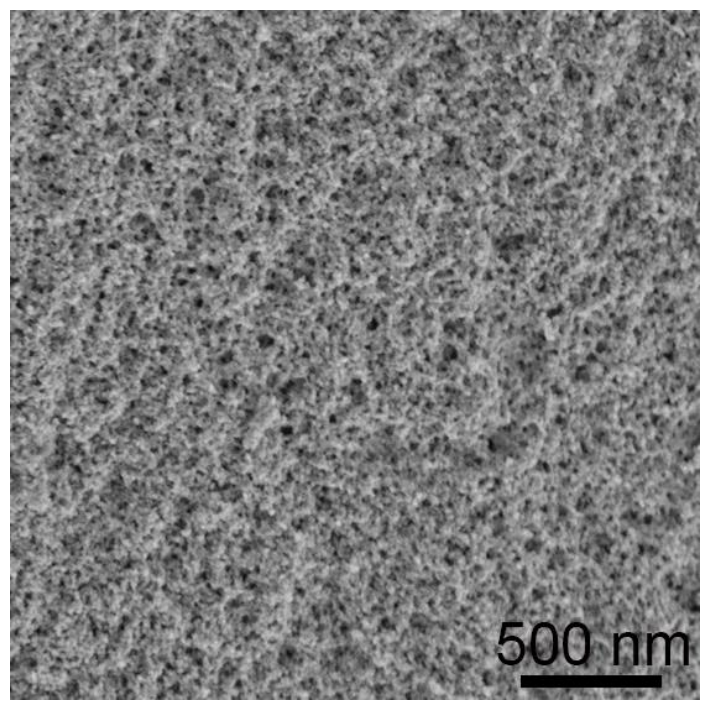

Figure S4. SEM image of PB NPs. 

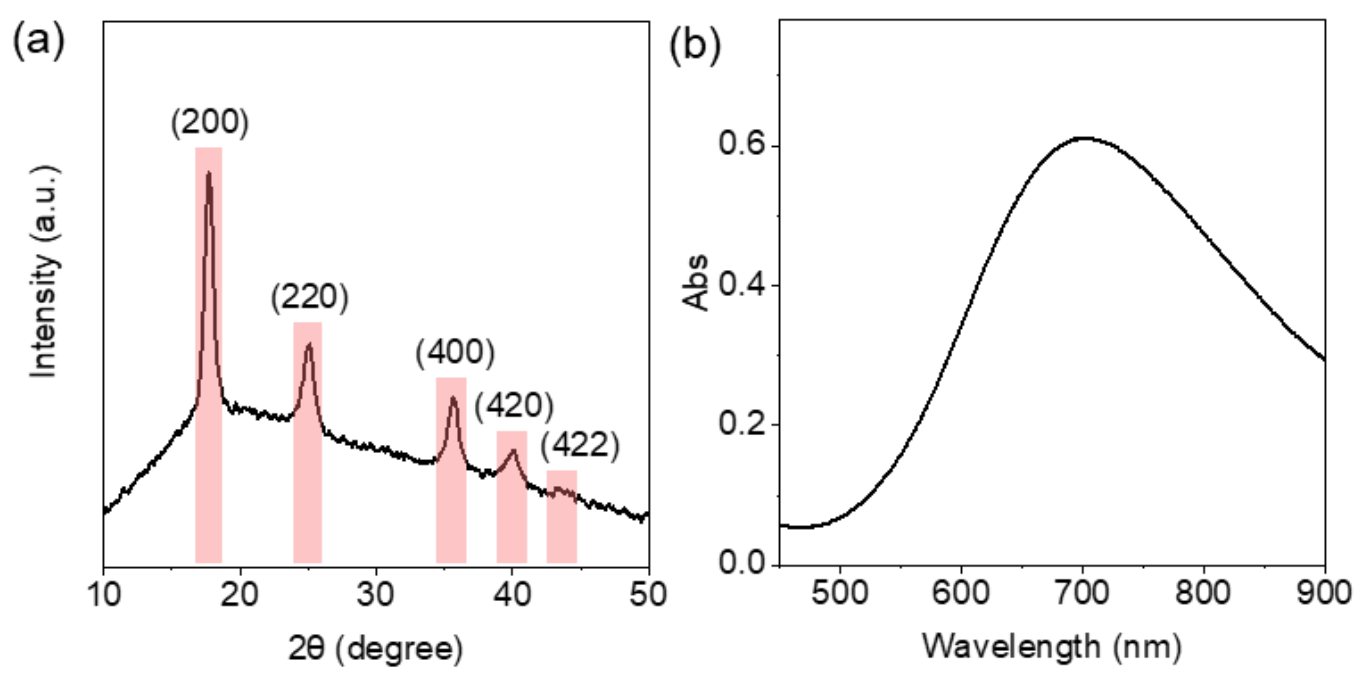

Figure S5. XRD spectrum (a) and UV-Vis spectrum (b) of PB NPs. 


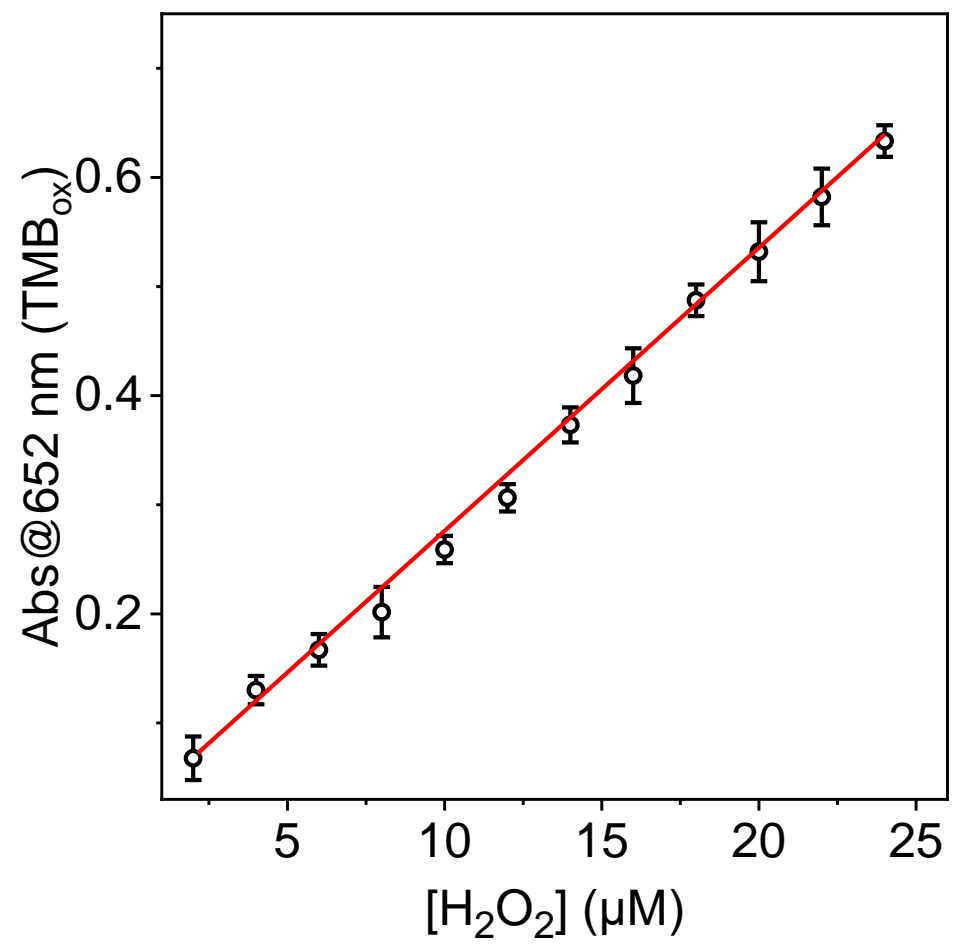

Figure S6. Calibration curve of $\mathrm{TMB}_{\mathrm{ox}}$ absorption intensity with different concentration of $\mathrm{H}_{2} \mathrm{O}_{2}$ by using PB NPs nanozyme. 

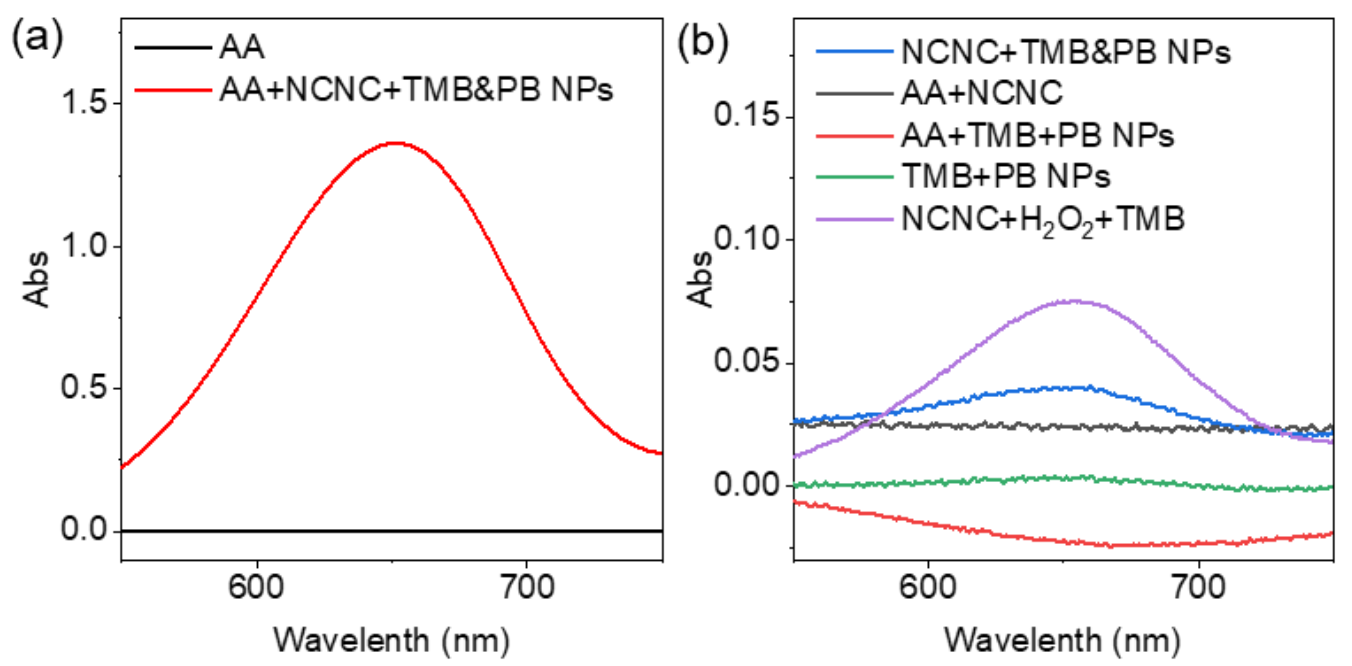

Figure S7. (a) UV-Vis absorption spectra of AA and $\mathrm{TMB}_{\text {ox }}$ catalyzed by PB NPs using the generated $\mathrm{H}_{2} \mathrm{O}_{2}$ during the catalyzation of AA $(50 \mu \mathrm{M})$ by NCNC. (b) UV-Vis absorption spectra of reaction solution under different experiment conditions: NCNC incubated with TMB and PB NPs; AA catalyzed by NCNC; AA incubated with TMB and PB NPs; TMB incubated with PB NPs; NCNC incubated with $\mathrm{H}_{2} \mathrm{O}_{2}$ and TMB.

The cascade reaction was proposed using NCNC and PB NPs as nanozymes. Firstly, $\mathrm{H}_{2} \mathrm{O}_{2}$ was generated when $\mathrm{NCNC}$ catalyzed oxidation of AA. Then, the blue $\mathrm{TMB}_{\text {ox }}$ was observed quickly through PB NPs catalyzed $\mathrm{H}_{2} \mathrm{O}_{2}$ to oxidize TMB (Figure S7a). Negligible absorbance at $652 \mathrm{~nm}$ was observed in the absence of AA, suggesting that no $\mathrm{TMB}_{\mathrm{ox}}$ was generated in the mixture of NCNC, TMB and PB NPs (Figure S7b). Furthermore, the absorbance intensity of $\mathrm{TMB}_{\mathrm{ox}}$ at $652 \mathrm{~nm}$ were also inappreciable under other experiment condition: AA catalyzed by NCNC; AA incubated with TMB and PB NPs; TMB incubated with PB NPs; NCNC incubated with $\mathrm{H}_{2} \mathrm{O}_{2}$ and TMB (Figure S7b). 


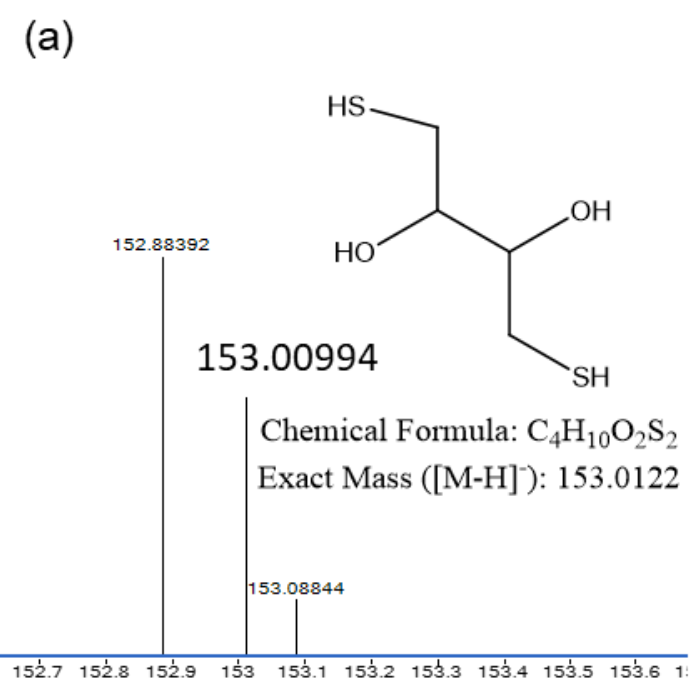

Counts (\%) vs. Mass-to-Charge $(\mathrm{m} / \mathrm{z})$ (b)<smiles>OC1CSSC[C@H]1O</smiles>

Chemical Formula: $\mathrm{C}_{4} \mathrm{H}_{8} \mathrm{O}_{2} \mathrm{~S}_{2}$ Exact Mass ([M-H] $\left.]^{-}\right): 150.9966$ 150.99549

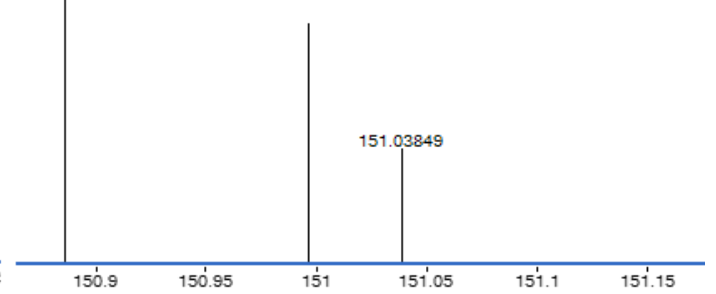

Counts (\%) vs. Mass-to-Charge $(\mathrm{m} / \mathrm{z})$

Figure S8. ESI-MS spectra of DDT (a) and DDT ${ }_{\text {ox }}(\mathrm{b})$. 
(a)

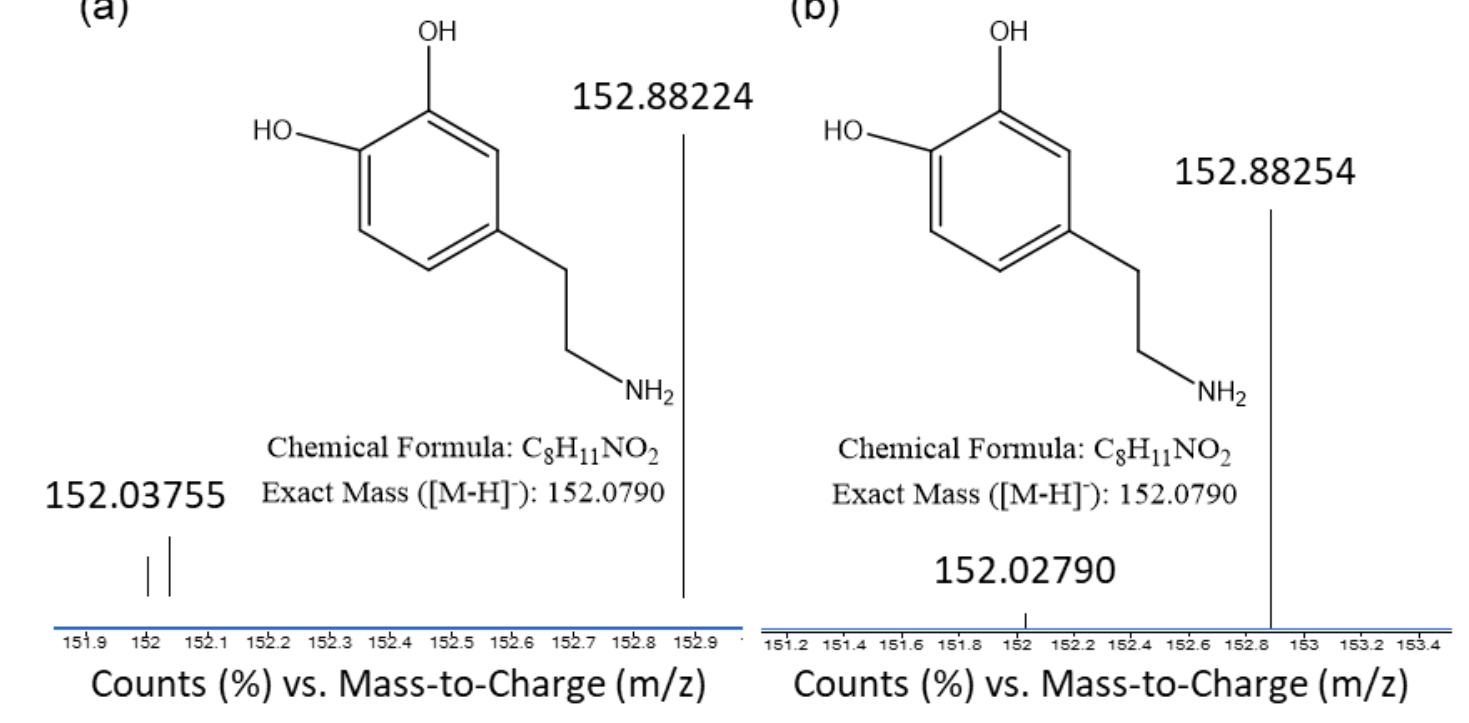

Figure S9. ESI-MS spectra of DA before (a) and after (b) catalytic oxidation by NCNC. 


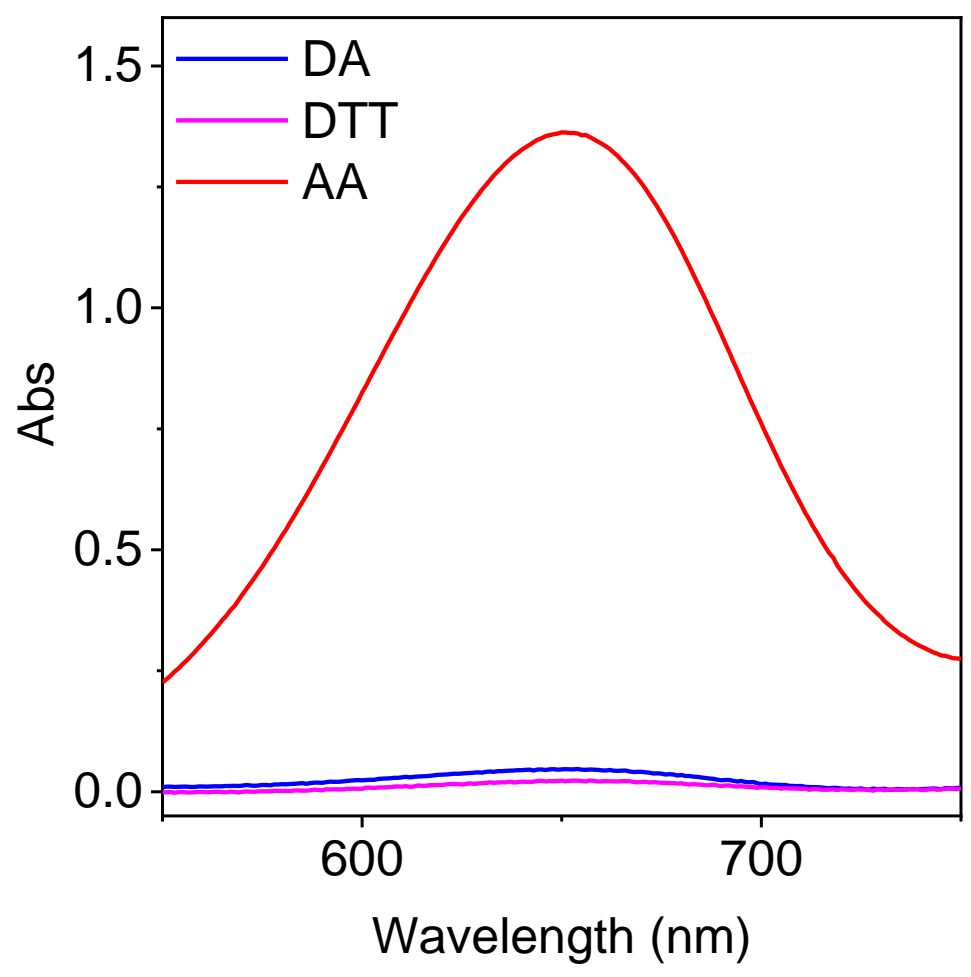

Figure S10. UV-Vis absorption spectra of $\mathrm{TMB}_{\mathrm{ox}}$ in the final reaction solution through the proposed cascade reaction (AA, DTT, and DA were catalyzed by NCNC, and TMB was catalyzed by PB NPs).

As shown in Figure S8, the EIS-MS spectral analysis demonstrated that the DTT $\left([\mathrm{M}-\mathrm{H}]^{-}=153.0122\right)$ was catalyzed oxidation by NCNC to generate the oxidized product $\mathrm{DTT}_{\mathrm{ox}}\left([\mathrm{M}-\mathrm{H}]^{-}=150.9966\right)$. But, the absorbance intensity of $\mathrm{TMB}_{\mathrm{ox}}$ was negligible when DTT and TMB were used as substrates of the proposed cascade reaction. These results suggested that DTT could be catalyzed oxidation by NCNC without generating $\mathrm{H}_{2} \mathrm{O}_{2}$. Moreover, the EIS-MS spectra of DA, before and after catalyzed by NCNC, showed the same characteristic peak (Figure S9), suggested that DA could not be catalyzed oxidized by NCNC. Therefore, the absorbance of $\mathrm{TMB}_{\mathrm{ox}}$ was hardly monitored (Figure S10). 


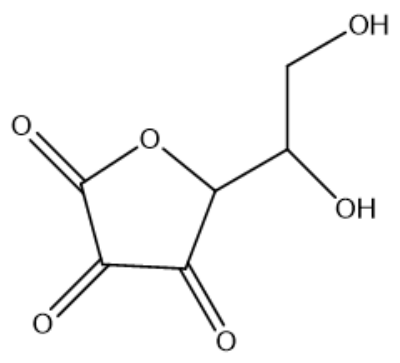

Chemical Formula: $\mathrm{C}_{6} \mathrm{H}_{6} \mathrm{O}_{6}$ Exact Mass ([M-H] $\left.]^{-}\right): 173.0164$

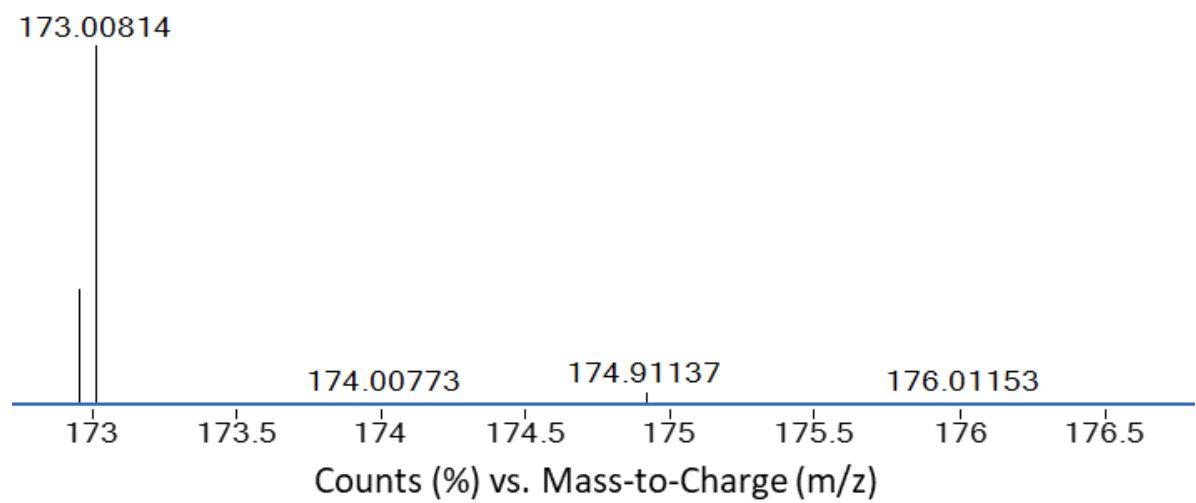

Figure S11. ESI-MS spectrum of AA after catalytic oxidation by NCNC. 


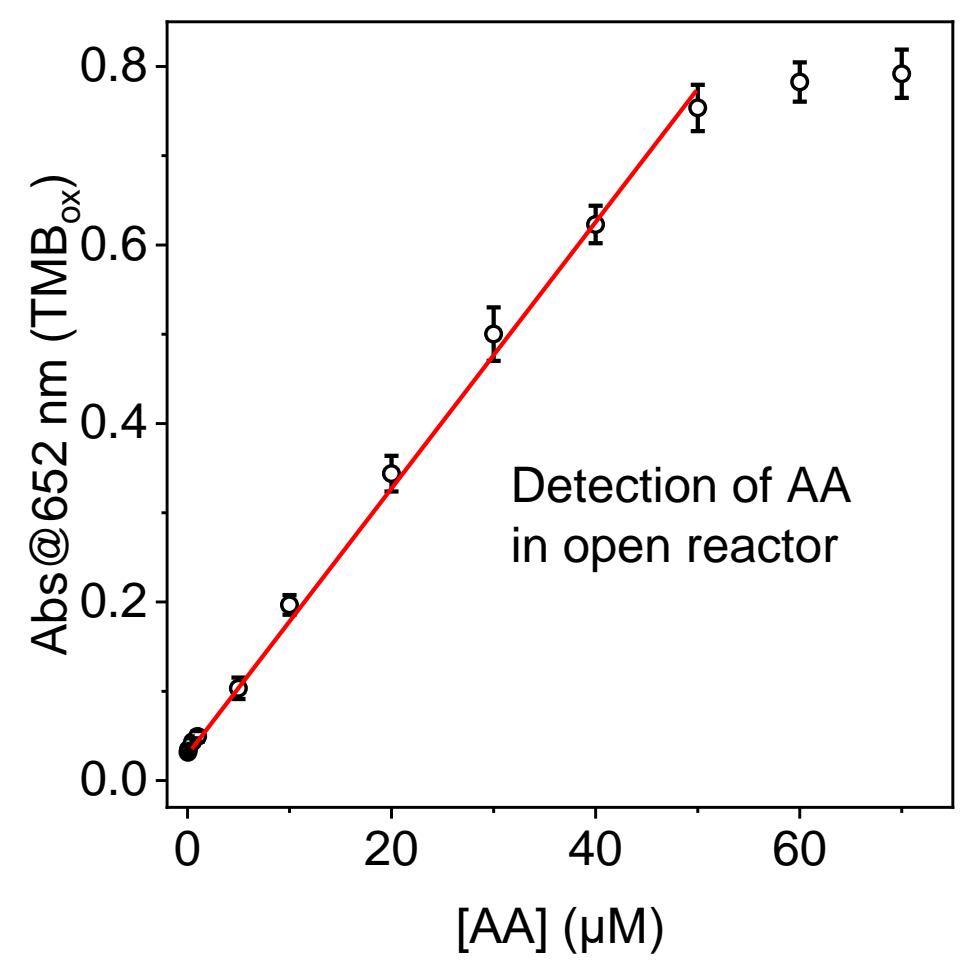

Figure S12. The calibration curve of detecting different concentration AA in open reactors.

Dual nanozyme cascade reaction was firstly carried out by NCNC and PB NPs in a open reactor with $\mathrm{AA}$ and $\mathrm{TMB}$ as substrates. The absorbance of blue $\mathrm{TMB}_{\text {ox }}$ at 652 nm was monitored by a UV-vis spectrophotometer, which could be used to calculate the concentrations of AA. The intensity of the absorption peak gradually increased with increasing the AA concentration, showing a good linearity ranging from $50 \mathrm{nM}$ to 50 $\mu \mathrm{M}$, with a detection limit of $20.4 \mathrm{~nm}$. 
Table 1. Comparison of colorimetric method for detection of AA using different nanozyme in the literatures.

\begin{tabular}{|c|c|c|c|c|}
\hline Method & Key feature & $\begin{array}{c}\text { Dynamic detection } \\
\text { range }(\mu \mathrm{M})\end{array}$ & LOD $(\mu \mathbf{M})$ & Ref \\
\hline colorimetry & $\begin{array}{l}\text { CoOOH-ABTS } \\
\text { oxidative system }\end{array}$ & $0.5-15$ & 0.16 & S5 \\
\hline colorimetry & $\begin{array}{c}\text { Oxidase-like } \\
\text { polyaniline- } \mathrm{MnO}_{2}\end{array}$ & $0.5-10$ & 0.026 & S6 \\
\hline colorimetry & $\begin{array}{l}\text { Peroxidase-like } \\
\text { GoldMag } \\
\text { nanocomposite }\end{array}$ & $10-1000$ & 0.12 & S7 \\
\hline colorimetry & $\begin{array}{l}\text { Peroxidase-like } \\
\mathrm{Co}_{3} \mathrm{O}_{4} / \text { graphene }\end{array}$ & $30-140$ & 0.19 & S8 \\
\hline colorimetry & $\begin{array}{l}\text { Peroxidase-like } \\
\text { MIL-100 }\end{array}$ & $30-485$ & 6 & S9 \\
\hline colorimetry & $\begin{array}{l}\text { NCNC\&PB NPs } \\
\text { cascade reaction }\end{array}$ & $0.01-50$ & 0.00132 & $\begin{array}{l}\text { This } \\
\text { work }\end{array}$ \\
\hline
\end{tabular}




\section{Supporting Reference}

(S1) Zhao, J.; Lai, H. W.; Lyu, Z. Y.; Jiang, Y. F.; Xie, K.; Wang, X. Z.; Wu, Q.; Yang, L. J.; Jin, Z.; Ma, Y. W.; Liu, J.; Hu, Z. Adv. Mat. 2015, 27, 3541.

(S2) Chung, H. T.; Cullen, D. A.; Higgins, D.; Sneed, B. T.; Holby, E. F.; More, K. L.; Zelenay, P. Science 2017, 357, 479.

(S3) Komkova, M. A.; Karyakina, E. E.; Karyakin, A. A. J. Am. Chem. Soc. 2018, 140, 11302.

(S4) Huang, W.; Deng, Y. Q.; He, Y. Biosens. Bioelectron. 2017, 91, 89.

(S5) Fang, X.; Wang, J.; Cui, X. Q.; Zhang, Y. H.; Zhu, R. F.; Zhao, H.; Li, Z. X. Colloid. Surface. A 2019, 575, 66-74.

(S6) Chi, M. Q.; Zhu, Y.; Jing, L. W.; Wang, C.; Lu, X. F. Talanta 2019, 191, 171-179.

(S7) Guan, H. N.; Han, B. L.; Gong, D. Z.; Song, Y.; Liu, B.; Zhang, N. Spectrochim. Acta. A 2019, 222, 9.

(S8) Fan, S. S.; Zhao, M. G.; Ding, L. J.; Li, H.; Chen, S. G. Biosens. Bioelectron. 2017, 89, 846-852.

(S9) Zhang, J. W.; Zhang, H. T.; Du, Z. Y.; Wang, X. Q.; Yua, S. H.; Jiang, H. L. Chem. Commun. 2014, 50, 1092-1094. 
